\title{
THE RIB-VERTEBRA ANGLE IN THE EARLY DIAGNOSIS BETWEEN RESOLVING AND PROGRESSIVE INFANTILE SCOLIOSIS*
}

\author{
M. H. Mehta, Calcutta, India
}

From the Institute of Orthopaedics and Royal National Orthopaedic Hospital, London

"Spontaneous correction does occur without treatment but at the moment it is not possible to distinguish between the two at the time of diagnosis."-Harrenstein (1930)

The problem of making an early diagnosis between resolving and progressive forms of infantile scoliosis has remained since Harrenstein's time. The quotation given is one of eight points summarising his observations on forty-six infants under the age of two years with structural scoliosis of unknown etiology with no vertebral or rib malformation to account for the deformity. The curves were preponderantly thoracic but nine infants had both thoracic and lumbar primary curves. In a few patients the curves corrected spontaneously; the others progressed despite early treatment.

James (1951) described the natural history of the progressive type and drew attention to the severe deformity at the end of growth in the untreated child due to a combination of early onset and rapid rate of progress. Scott and Morgan (1955) showed that resolving curves were not uncommon. James, Lloyd-Roberts and Pilcher (1959), reporting the outcome of infantile structural scoliosis in 212 patients, found that although resolving curves were generally long curves of less than 35 degrees, there were no absolute criteria for distinguishing them. By 1965 Lloyd-Roberts and Pilcher were still unable to differentiate between resolving and progressive curves in 100 babies with untreated scoliosis except by observing them over a few months and noting the outcome. Conner (1969) found that an infantile scoliosis associated with a developmental anomaly is likely to progress.

It is with the problem of early detection of progressive curves that this paper is concerned. The aim is to present firstly, a radiological method for differentiating between resolving and progressive curves at an early age, and secondly, to examine the influence of the early growth spurt upon progressive curves in order to stress the importance of early detection.

\section{METHOD}

Clinical notes and radiographs of all patients with infantile scoliosis at the Royal National Orthopaedic Hospital were searched. Altogether 361 complete clinical records including radiographs taken before the age of two years were found. The mothers of 175 such patients living within convenient travelling distance of the hospital were invited to bring their children for review; 138 attended. The study was in two parts, clinical and radiological; in this paper only the latter will be described.

The radiological study consisted of a re-examination of the films of each patient with the primary object of following the evolution of the spinal deformity. However, certain differences noticed in the relationship of the ribs to the vertebrae in resolving and in progressive curves led to a careful inspection of the rib-vertebra area in all radiographs, and despite the similarity of the curves in films it became possible to distinguish the two groups. To demonstrate these slight differences a method of measurement of the rib-vertebra angle was evolved.

For describing the rib-vertebra relationship in scoliosis certain terms are introduced which need to be defined. The rib-vertebra or $R-V$ angle is the angle formed between each side of

\footnotetext{
* This paper is based on part of the Robert Jones Prize Essay for 1968.
} 
the apical thoracic vertebra and its corresponding rib. The rib-vertebra angle difference is the difference between the values of the R-V angles on the concave and convex sides of a curve at any given level.

Phase 1 -This is an early stage in a scoliosis when in an antero-posterior radiograph the head of the apical rib on the convex side of a curve is seen to be distinct from the upper corner of the apical vertebra (Fig. 1). The R-V angle is measured when the apical rib head is in Phase 1. Phase 2-This is the next stage in a progressive scoliotic deformity, when the rib shadow overlaps the upper corner (Fig. 2).

The rib-vertebra relationship in the normal spine-In an antero-posterior radiograph two features may be noted. 1) The rib-vertebra angles formed on either side of a vertebra are equal (Figs. 3 and 4). 2) A gap of 2 to 4 millimetres separates the head of the rib and the upper corner of the corresponding vertebra; in other words the rib head is in Phase 1.
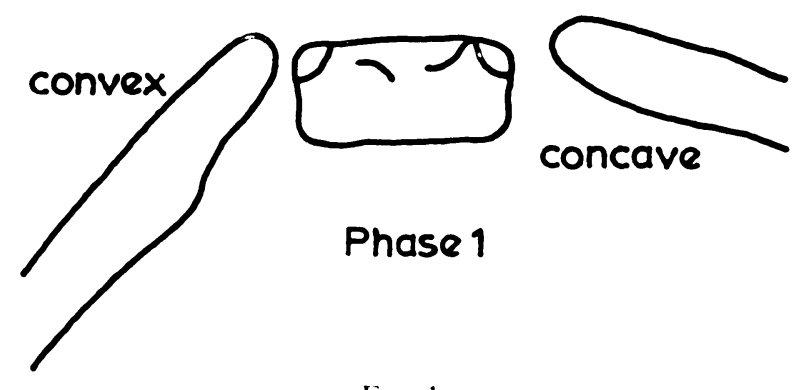

Fik. 1

The outlines of the apical vertebra and ribs at an early stage of scoliosis.

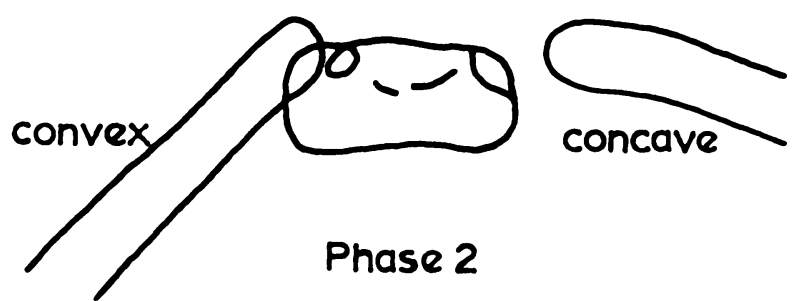

FIG. 2

The outlines at a later stage, showing overlap of rib and vertebra.

Measurement of the R-V angle-A perpendicular is drawn to the middle of either the upper or lower border of a selected thoracic vertebra (in a scoliotic curve the apical vertebra). This is the datum line for that vertebra. Another line is drawn from the mid-point of the head of the rib to the mid-point of the neck of the rib, just medial to the region where the neck widens into the shaft of the rib. This rib line is extended medially to intersect the vertebral line to make the R-V angle (Fig. 4).

\section{RESULTS}

The rib-vertebra relationship in the early stages of scoliosis-In progressive infantile scoliosis the commonest patterns are thoracic and double thoracic and lumbar primary curves; thoracolumbar curves are infrequent. Resolving curves are predominantly thoracic, rarely double. The early differential diagnosis is therefore largely a matter of recognition of resolving and progressive thoracic curves. It has been found that each curve pattern has a characteristic rib-vertebra relationship recognisable from the earliest radiographs.

VOL. 54 B, NO. 2, MAY 1972 
I propose to describe the rib-vertebra relationship in thoracic curves and then to show the difference in the rib-vertebra relationship between resolving and progressive curves of the thoracic pattern, and finally to describe the typical rib-vertebra arrangement in double curves.

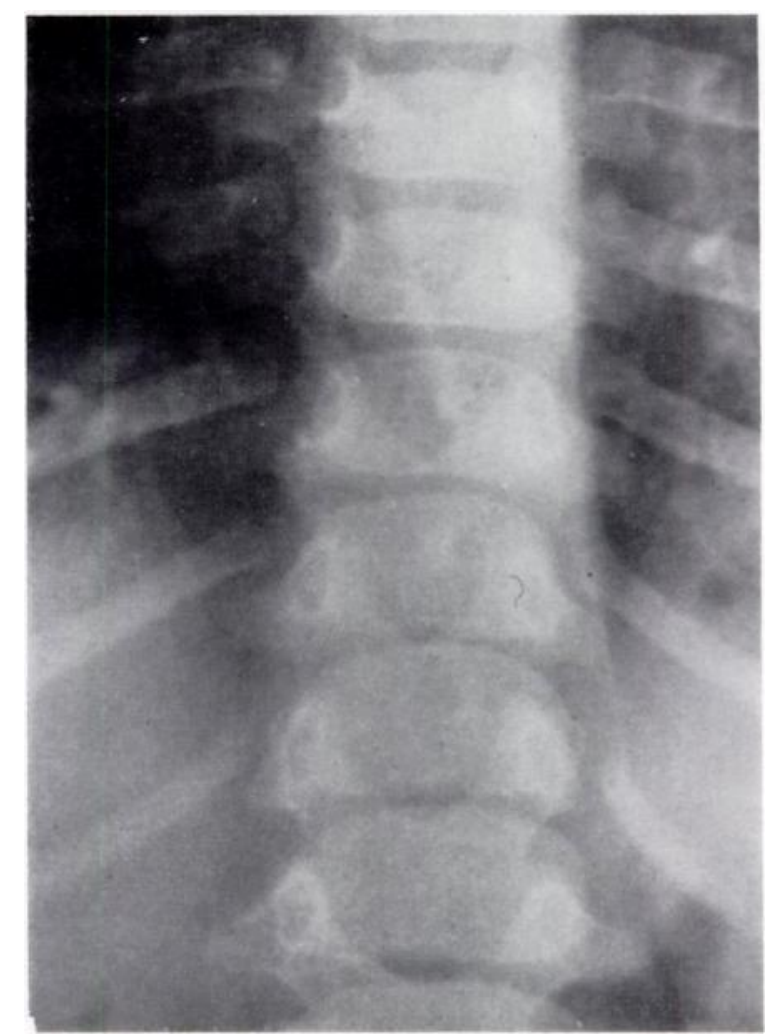

Fig. 3

Antero-posterior radiograph of an infant aged 12 months illustrating the rib-vertebra relationship in a normal spine. Note 1) the symmetry of the ribs, 2) the separate shadows of the heads of the ribs an 1 adjacent corners of the numerically corresponding vertebrae, as in Phase 1 of scoliosis.
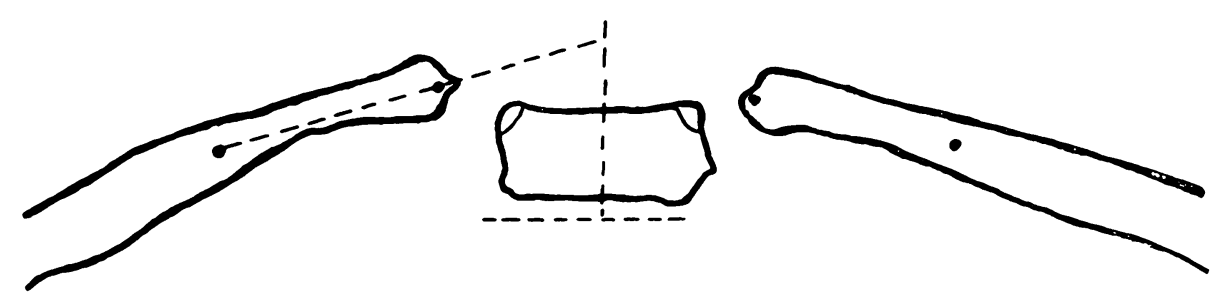

Fig. 4

The construction of the rib-vertebra angle

In scoliosis of the thoracic (or thoraco-lumbar) pattern the normal rib-vertebra relationship is altered in a well-ordered sequence. The earliest observable effect upon the thoracic cage is an increased downward obliquity of the ribs on the convex as compared with the concave side, maximal at the apex of the curve. Measurement of the R-V angles at the apex therefore reveals a lesser angle on the convex side. The difference between the angles is an expression 
of the degree of obliquity of the convex side ribs associated with a thoracic or thoraco-lumbar scoliosis. At this early stage the shadows of the head of the apical rib on the convex side and of the apical vertebra are clearly separate; the rib head is in Phase 1 (Fig. 5).

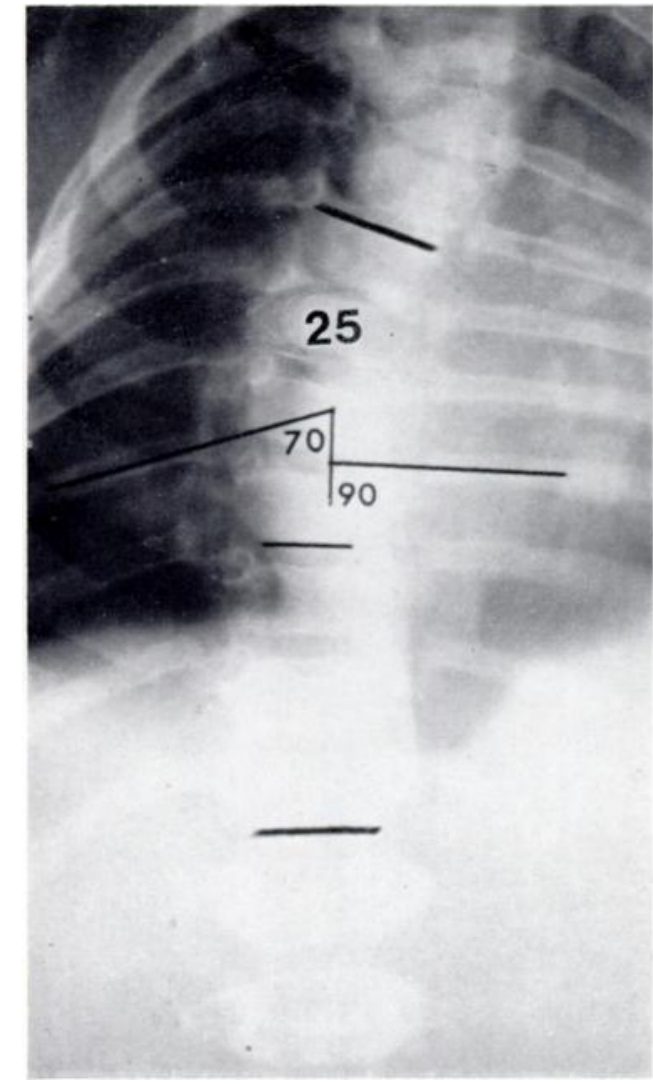

FIG. 5

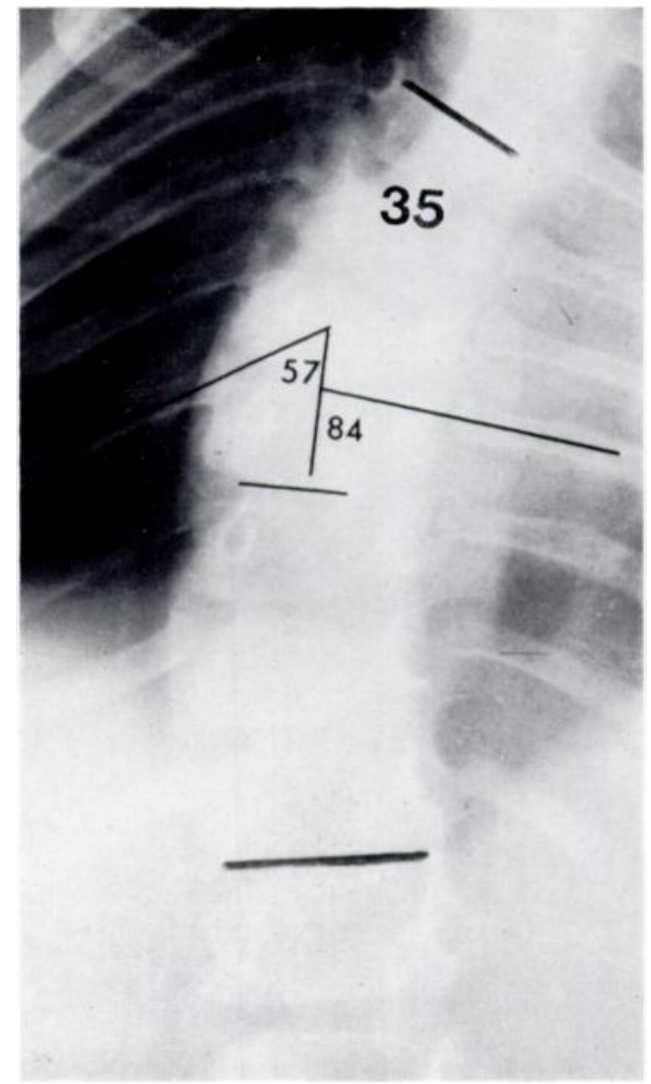

FiG. 6

To illustrate the early stages of progressive infantile scoliosis. Figure 5-Radiograph of a mild curve in a boy of 5 months. The convex side apical rib head, the ninth, is in Phase 1 . The rib-vertebra angle difference is 20 degrees. Figure 6-Radiograph of the same child at the age of 14 months showing the apical rib head in Phase 2, superimposed upon the upper corner of the vertebra. The rib-vertebra angle difference is now

$$
27 \text { degrees. }
$$

The next stage in the progression of an early scoliosis is reached when the shadow of the head of the apical rib on the convex side overlaps the upper corner of the corresponding vertebral body; the rib head is now regarded as being in Phase 2 (Fig. 6). In all the radiographs reviewed spontaneous resolution did not occur in any curve, however small, in which the rib head was in Phase 2. Because Phase 2 is the hall-mark of definitive progressive scoliosis it follows that for an early diagnosis between resolving and progressive curves a distinction should be attempted while the rib head in both types is still in Phase 1. This can be achieved by measurement of the R-V angles.

The difference between resolving and progressive scoliosis in Phase 1-The conclusions reached at the end of this section have been obtained by studying the early radiographs of forty-six known cases of resolving and forty of progressive scol:osis. In each patient the standard method adopted was to measure the R-V angle difference at the apex on the first available radiograph and on every subsequent radiograph till the outcome was clear, namely a straight 
spine in the resolving group or entry of the apical rib head into Phase 2 in the progressive group. By applying this method of measurement certain striking differences in behaviour were revealed between the resolving and progressive groups. These differences are related to 1) the magnitude of the R-V angle difference on the first radiograph, and 2) the manner in which this initial R-V angle difference becomes altered subsequently.

TABLE I

Resolving Curves of Less than 20 Degrees

\begin{tabular}{|c|c|c|c|c|}
\hline $\begin{array}{c}\text { Case } \\
\text { number }\end{array}$ & Sex & $\begin{array}{c}\text { Age at first } \\
\text { radiograph } \\
\text { (months) }\end{array}$ & $\begin{array}{c}\text { Angle of } \\
\text { curve } \\
\text { (degrees) }\end{array}$ & $\begin{array}{c}\text { Initial } \\
\text { rib-vertebra } \\
\text { angle difference } \\
\text { (degrees) }\end{array}$ \\
\hline 1 & Male & 8 & 18 & 16 \\
\hline 2 & Male & 12 & 12 & 15 \\
\hline 3 & Female & 4 & 19 & 12 \\
\hline 4 & Female & 4 & 15 & 14 \\
\hline 5 & Male & 8 & 17 & 5 \\
\hline 6 & Male & 6 & 14 & 8 \\
\hline 7 & Female & 7 & 11 & 11 \\
\hline 8 & Female & 11 & 12 & 12 \\
\hline 9 & Female & 13 & 12 & 15 \\
\hline 10 & Male & 9 & 13 & 12 \\
\hline 11 & Male & 13 & 10 & 3 \\
\hline 12 & Male & 12 & 8 & 26 \\
\hline 13 & Male & 12 & 8 & 5 \\
\hline 14 & Female & 5 & 19 & 6 \\
\hline 15 & Male & 4 & 12 & 11 \\
\hline 16 & Male & 12 & 10 & 3 \\
\hline 17 & Male & 9 & 16 & 9 \\
\hline 18 & Male & 21 & 12 & 20 \\
\hline 19 & Male & 8 & 8 & 14 \\
\hline 20 & Female & 8 & 13 & $-5 *$ \\
\hline 21 & Female & 6 & 15 & 21 \\
\hline 22 & Male & 11 & 13 & 24 \\
\hline 23 & Female & 12 & 16 & 7 \\
\hline
\end{tabular}

* The rib-vertebra angle difference is termed negative when the angle on the concave side is less than that on the convex side, indicating a greater rib droop along the concavity of the curve.

Tables I, II and III list the initial R-V angle differences in resolving and in progressive scoliosis. Resolving curves of less than 20 degrees are grouped in Table I and those measuring 20 degrees or more are listed in Table II. Table III is derived from eighteen selected cases of progressive thoracic scoliosis; no curve in this group exceeded 38 degrees, thereby making the cases roughly comparable to the resolving curves listed in Table II. 
Tables I and II show that whereas in the majority ( 83 per cent) of resolving curves the initial R-V angle difference is less than 20 degrees, a proportion of cases (17 per cent) shows an $\mathrm{R}-\mathrm{V}$ angle difference of 20 degrees and more.

TABLE II

Resolving Curves of 20 Degrees and Over

\begin{tabular}{|c|c|c|c|c|}
\hline $\begin{array}{c}\text { Case } \\
\text { number }\end{array}$ & Sex & $\begin{array}{l}\text { Age at first } \\
\text { radiograph } \\
\text { (months) }\end{array}$ & $\begin{array}{c}\text { Angle of } \\
\text { curve } \\
\text { (degrees) }\end{array}$ & $\begin{array}{c}\text { Initial } \\
\text { rib-vertebra } \\
\text { angle difference } \\
\text { (degrees) }\end{array}$ \\
\hline 24 & Female & 2 & 29 & 6 \\
\hline 25 & Male & 16 & 22 & 4 \\
\hline 26 & Male & 5 & 26 & 23 \\
\hline 27 & Male & 6 & 28 & 0 \\
\hline 28 & Male & 5 & 26 & 15 \\
\hline 29 & Male & 5 & 22 & $-5^{*}$ \\
\hline 30 & Male & 4 & 40 & 17 \\
\hline 31 & Male & 12 & 38 & 17 \\
\hline 32 & Male & 8 & 20 & 0 \\
\hline 33 & Male & 5 & 30 & 27 \\
\hline 34 & Female & 3 & 22 & 18 \\
\hline 35 & Male & 7 & 27 & 20 \\
\hline 36 & Male & 13 & 21 & $-1 *$ \\
\hline 37 & Male & 5 & 20 & 11 \\
\hline 38 & Male & 20 & 30 & 13 \\
\hline 39 & Male & 6 & 25 & 10 \\
\hline 40 & Male & 9 & 23 & 6 \\
\hline 41 & Female & 8 & 20 & 22 \\
\hline 42 & Male & 6 & 20 & 18 \\
\hline 43 & Male & 14 & 37 & 18 \\
\hline 44 & Male & 10 & 23 & 9 \\
\hline 45 & Female & 4 & 52 & 18 \\
\hline 46 & Male & 12 & 22 & 10 \\
\hline
\end{tabular}

* The rib-vertebra angle difference is termed negative when the angle on the concave side is less than that on the convex side, indicating a greater rib droop along the concavity of the curve.

Table III reveals that most progressive curves have an initial $\mathrm{R}-\mathrm{V}$ angle difference of 20 degrees or more but that in a few (17 per cent) this is under 20 degrees.

From these tables it may be concluded that, in general, the initial R-V angle difference in resolving curves is smaller that in progressive curves. The critical value appears to be about 20 degrees. It would therefore seem reasonable to suggest that any curve with an initial $\mathrm{R}-\mathrm{V}$ angle difference of 20 degrees or more must be regarded as potentially progressive until 
proved otherwise at a subsequent examination. No more than this can be said about the nature of the curve from the first radiograph.

It is only from a subsequent radiograph taken after an interval of three months-a length of time sufficient to allow the deformity to reveal its nature-that a definite diagnosis of resolving or of progressive scoliosis can be reached by comparing the $R-V$ angle value with the previous readings. In all forty-six cases of resolving scoliosis the $\mathrm{R}-\mathrm{V}$ angle difference diminished progressively as the ribs became increasingly symmetrical (Figs. 7 and 8), and this despite a temporary increase in the curvature observed in two cases (Figs. 9 to 11). In

TABLE III

Progressive Infantile Thoracic Scoliosis

\begin{tabular}{|c|c|c|c|c|c|}
\hline $\begin{array}{c}\text { Case } \\
\text { number }\end{array}$ & Sex & $\begin{array}{l}\text { Age at first } \\
\text { radiograph } \\
\text { (months) }\end{array}$ & $\begin{array}{l}\text { Angle of } \\
\text { curve } \\
\text { (degrees) }\end{array}$ & $\begin{array}{c}\text { Initial } \\
\text { rib-vertebra } \\
\text { angle difference } \\
\text { (degrees) }\end{array}$ & Phase \\
\hline 47 & Male & 24 & 32 & 33 & 1 \\
\hline 48 & Female & 6 & 14 & 21 & 1 \\
\hline 49 & Male & 5 & 25 & 20 & 1 \\
\hline 50 & Male & 20 & 24 & 32 & 1 \\
\hline 51 & Male & 10 & 22 & 18 & 1 \\
\hline 52 & Male & 18 & 35 & 43 & 1 \\
\hline 53 & Female & 11 & 22 & 18 & 1 \\
\hline 54 & Male & 10 & 38 & 28 & 2 \\
\hline 55 & Male & 13 & 38 & 38 & 1 \\
\hline 56 & Male & 21 & 26 & 20 & 1 \\
\hline 57 & Male & 5 & 26 & 20 & 1 \\
\hline 58 & Male & 9 & 32 & 21 & 1 \\
\hline 59 & Female & 11 & 12 & 28 & 1 \\
\hline 60 & Male & 10 & 27 & 23 & 1 \\
\hline 61 & Male & 11 & 36 & 27 & 1 \\
\hline 62 & Female & 14 & 35 & 23 & 1 \\
\hline 63 & Male & 20 & 23 & 19 & 1 \\
\hline 64 & Male & 24 & 36 & 29 & 1 \\
\hline
\end{tabular}

the forty progressive cases the R-V angle difference either remained unchanged or increased (Figs. 12 to 14). Some cases which had progressed rapidly during the interval showed a transition from Phase 1 to Phase 2 in the rib-vertebra relationship.

These findings may be summarised thus:

Resolving scoliosis-1) In about 80 per cent of the cases the initial R-V angle difference is less than 20 degrees; in the remaining 20 per cent it exceeds 20 degrees; and 2) three months later the R-V angle difference is reduced, even if the curve itself shows an increase.

Progressive scoliosis-1) In about 80 per cent of cases the initial R-V angle difference is 20 degrees or over; in the remaining 20 per cent it is less than 20 degrees; 2) three months later the R-V angle difference is either the same or greater; and 3) a transition from Phase 1 to Phase 2 in rib-vertebra relationship marks an established progressive scoliosis. 
THE RIB-VERTEBKA RELATIONSHIP IN EARLY DOUBLE THORACIC AND LUMBAR CURVES

Double thoracic and lumbar curves show a characteristic rib-vertebra arrangement from the very early stages of the deformity by which it is possible to recognise the curve pattern even when the spinal curves themselves are not sufficiently developed to suggest this. A feature of double curves is that the thoracic is almost invariably ahead of the lumbar in both size and in degree of rotation. At times early radiographs of infantile scoliosis of the double curve pattern show a thoracic curve only, the true nature of the deformity being recognised only later with the formation of a lumbar curve. Such an error can be avoided, however, by recognising the characteristic rib-vertebra arrangement.

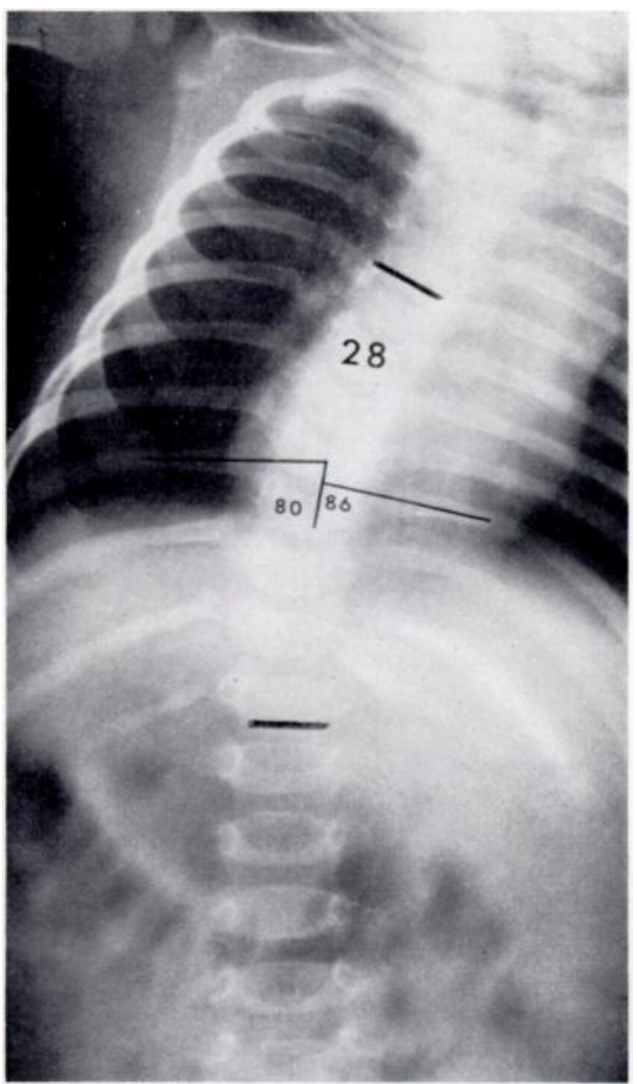

Fig. 7

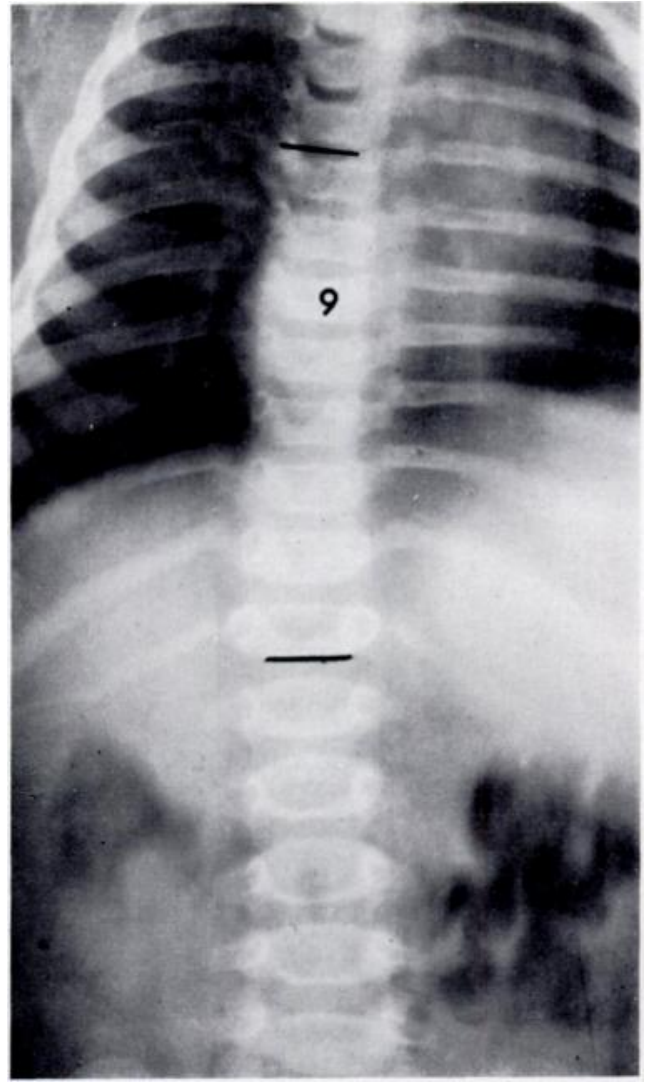

FIG. 8

Radiographs of an infant with spontaneously resolving scoliosis. Figure 7-At two months the small rib-vertebra angle difference of 6 degrees at the apex suggests a resolving scoliosis. Figure 8-The radiograph taken three months later confirms resolution.

The three features here described were observed in the early radiographs of all forty cases of progressive scoliosis of this pattern (Figs. 15 and 16). 1) The ribs on either side of the vertebrae forming the thoracic curve are generally horizontal, arched slightly upwards and very nearly symmetrical. Consequently the $\mathrm{R}-\mathrm{V}$ angle difference at the apex of the thoracic curve is small; it may be nil or even a negative figure. This initial appearance of a single thoracic curve with a small $\mathrm{R}-\mathrm{V}$ angle difference at the apex might suggest a resolving scoliosis of thoracic pattern. However, the presence of other features prevents such a mistake. 2) In contrast with the near symmetry of the apical ribs the twelfth pair of ribs, and to a lesser extent the eleventh pair also, shows a marked asymmetry, consisting of a downward droop of the rib on the concave side of the thoracic curve. The R-V angle difference at the twelfth 


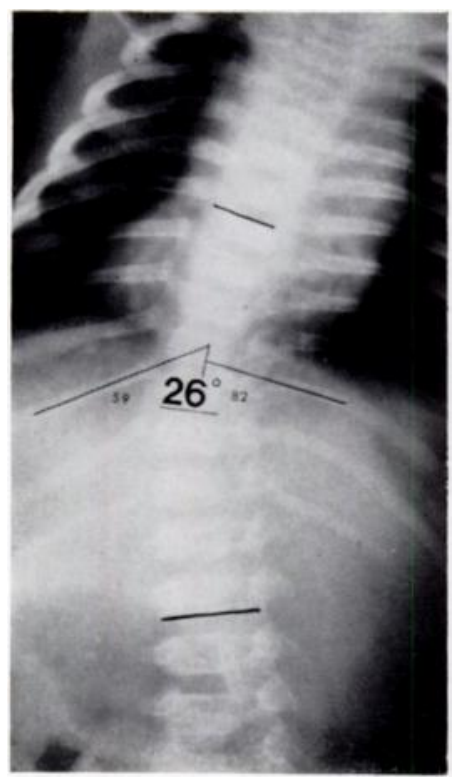

FIG. 9

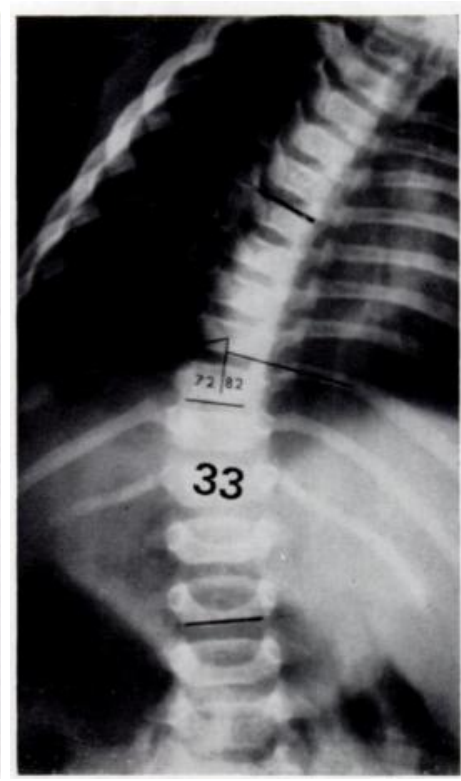

FIG. 10

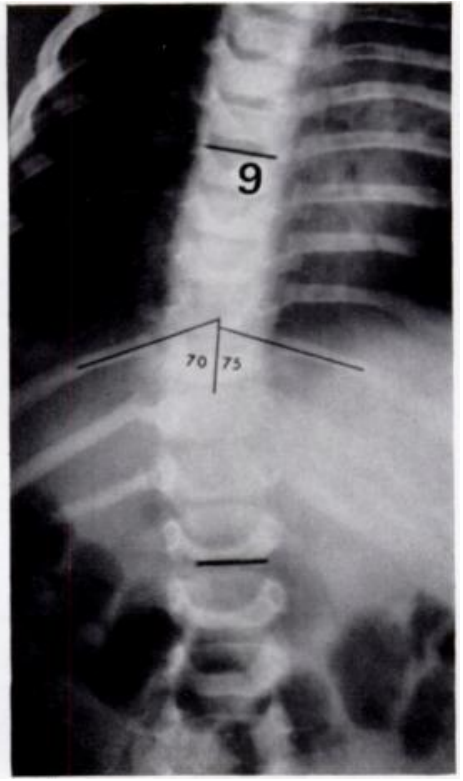

Fig. 11

A case of resolving infantile scoliosis. Figure 9-At 5 months a rib-vertebra angle difference of 23 degrees indicates an uncertain prognosis-the curve could either progress or resolve. Figure 10-At 8 months, despite an increase in curve measurement, the reduction of the angle difference of 10 degrees strongly suggests a diagnosis of resolving scoliosis. Figure 11 -At 11 months the diagnosis of resolving scoliosis is confirmed.

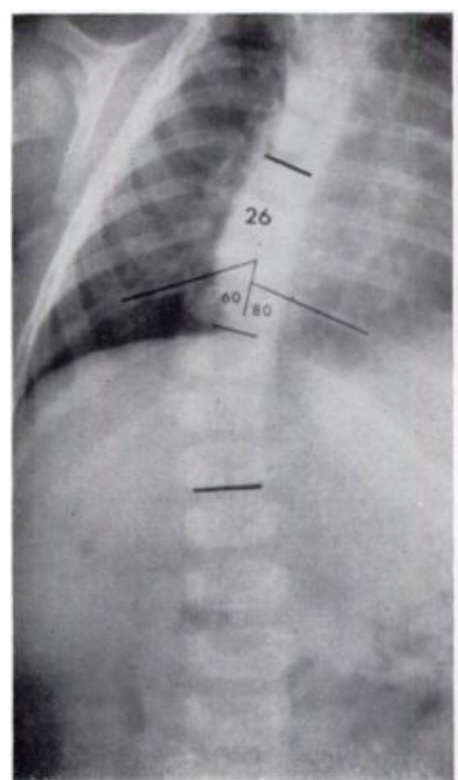

FIG. 12

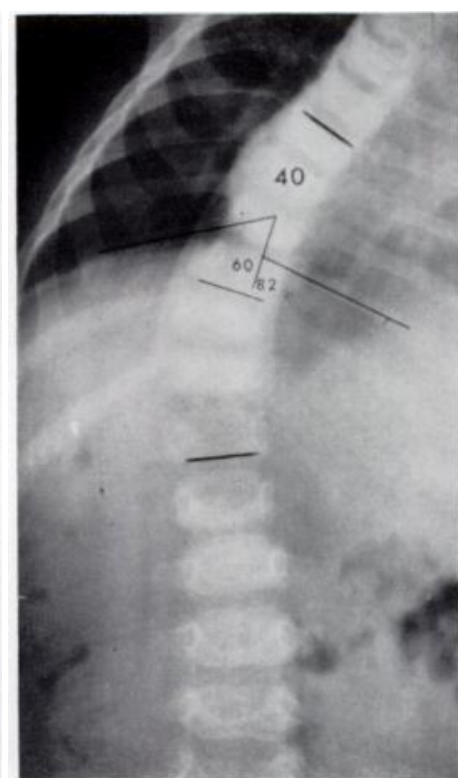

Fig. 13

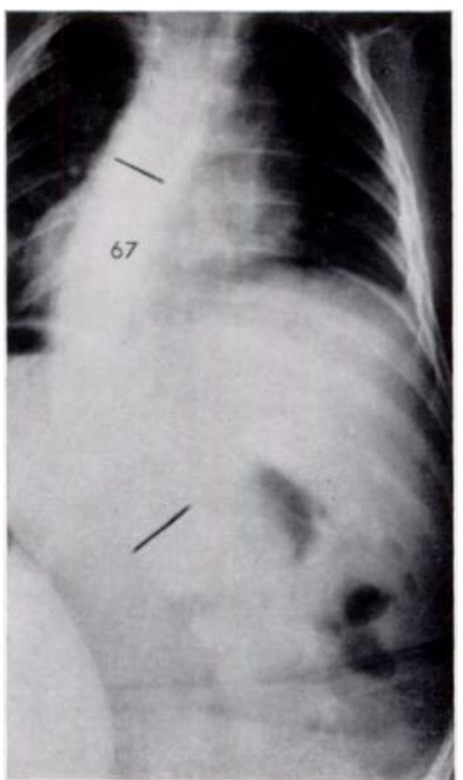

FIG. 14

A case of progressive infantile scoliosis. Figure 12-At 5 months with a rib-vertebra angle difference of 20 degrees the prognosis is uncertain. Figure 13-At 7 months an undoubtedly progressive curve is indicated by a slight increase in the angle difference and the appearance of the rib head on the convex side in Phase 2. Figure 14 At the age of 1 year the radiograph shows severe deformity with marked rotation. 
thoracic level is therefore always a negative figure. 3) The radiograph always reveals rotation in the thoracic curve and minimal rotation in an opposite direction in the lumbar vertebrae. This lumbar rotation is present even before the curve becomes radiographically evident.

In summary, the radiographic features characteristic of early double curves are: a single thoracic curve with a near symmetrical arrangement of the apical ribs, a downward droop of the twelfth rib on the concave side of the curve, and vertebral rotation in opposite directions in thoracic and lumbar vertebrae.

\section{THE INFLUENCE OF GROWTH ON PROGRESSIVE INFANTIIE SCOI.IOSIS}

The need to diagnose progressive scoliosis as early as possible can be fully appreciated only when the effect of growth rate in infancy upon the evolution of the deformity is critically examined.

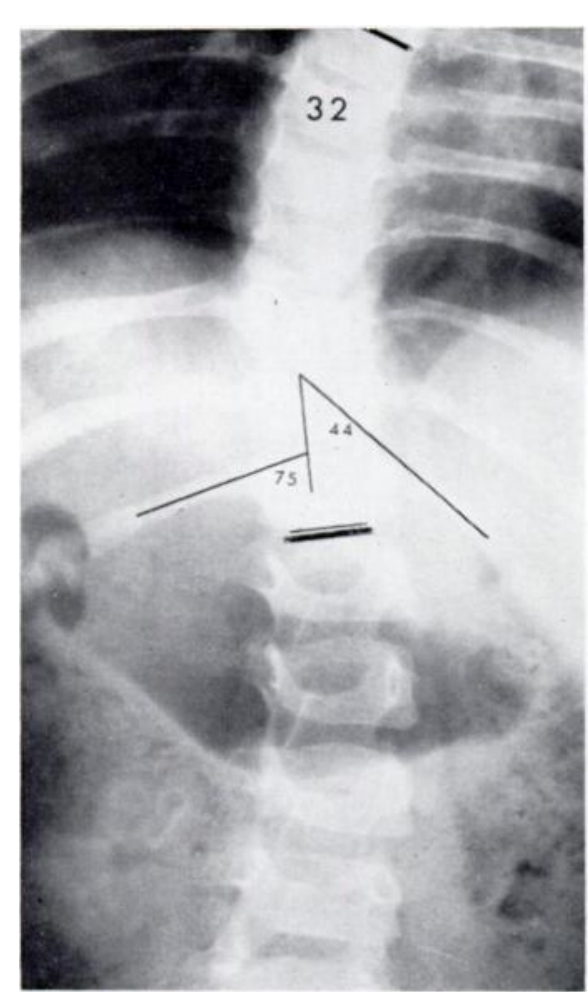

Fig. 15

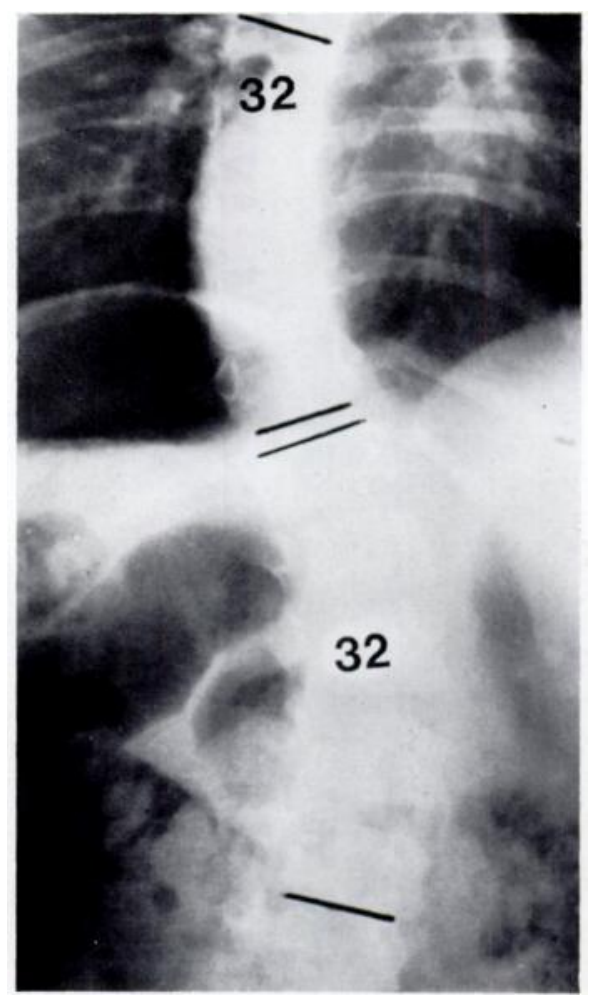

Fig. 16

A case of progressive infantile scoliosis of the combined thoracic and lumbar curve pattern. Figure 15-A radiograph taken supine at two years showing the typical features of an early combined curve, namely 1) symmetrical rib arrangement at the apex of the thoracic curve, 2) a negative rib-vertebra angle difference of 31 degrees at T.12 level, and 3) rotation of both thoracic and lumbar vertebrae. Figure 16--The double curves are clearly seen in the erect view taken two months later.

The usual indices for evaluating growth are those of height and weight measurements, standards for which in normal children of both sexes are obtainable as height-weight growth charts, expressed as increments of growth at all ages. These charts show that from birth to maturity a child passes through two periods of accelerated growth, the first from birth to two years. Examination of the rate of growth during this period reveals that the greatest gain in height and weight takes place from birth to one year. The maximum gain is in the first six months, so that by the end of the first year the baby has trebled his birth weight and increased his birth length by about 20 per cent (Watson and Lowrey 1967). During the second 
year the rate of increment in both height and weight is only about half that of the first year. Between two and four years the rate is further slowed down. From the age of four until adolescence the child is in a quiet growth phase, during which the average annual gain in height is a steady 5 to 6 centimetres. At adolescence, approximately ten to twelve years in girls and twelve to fourteen years in boys, there is again a sudden acceleration of growth.

In the present study the angles of curvature measured on radiographs of children with progressive infantile scoliosis throughout their growing years were charted as curve progression
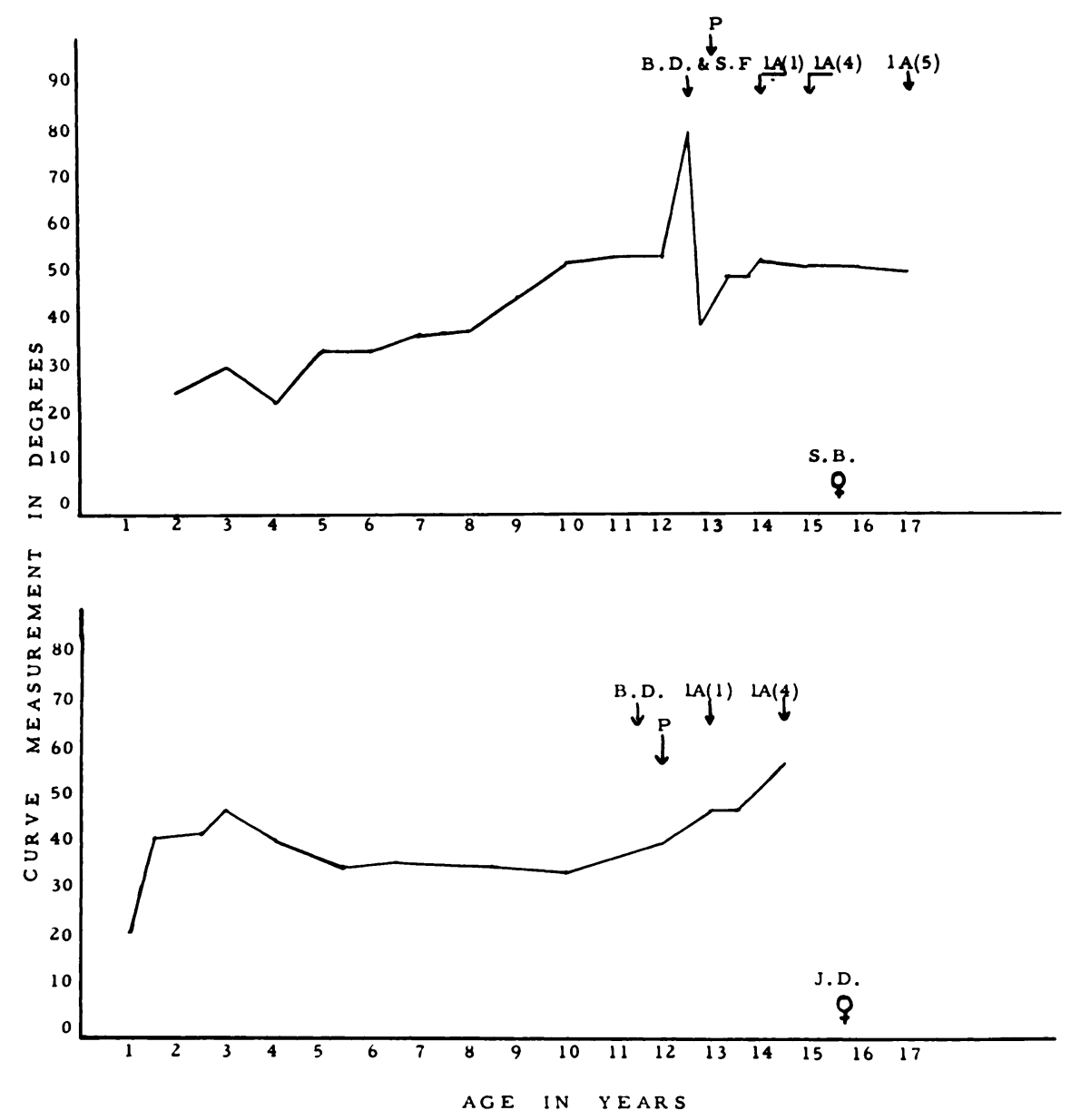

FIG. 17

Progression graphs of two benign progressive infantile curves showing the general pattern of progression in relation to growth and maturity. (B.D. = breast development; $P=$ periods; $1 \mathrm{~A}(1)=$ commencing ossification in the iliac apophysis; $1 \mathrm{~A}(4)=$ full ossification of iliac apophysis; S.F.=spinal fusion.)

graphs. It was found that the graphs varied: in some children the rate of progress was relatively mild compared with others in whom the curves were severe. On the basis of this variable severity of the curve and also on the basis of distinct clinical differences, which will be described in a separate paper, it was possible to classify progressive infantile scoliosis into two groupsbenign and malignant. Figures 17 and 18 illustrating progression graphs of benign and malignant curves show that although the severity of the curves differs, the general pattern of progress in both types is similar. A plateau corresponding to the steady quiet growth phase from four to nine or ten years intervenes between the two peaks in infancy and adolescence. The graphs also show that the heights of the plateau and of the adolescent peak are directly 
influenced by the height of the initial rise in infancy. It is important to recognise this feature and to note that curve increase during the infantile growth spurt, especially in malignant progressive curves, can be as great and as serious as that occurring in the adolescent growth phase. Figure 19 illustrates the almost vertical ascent of the curve angles in three severe progressive infantile curves.

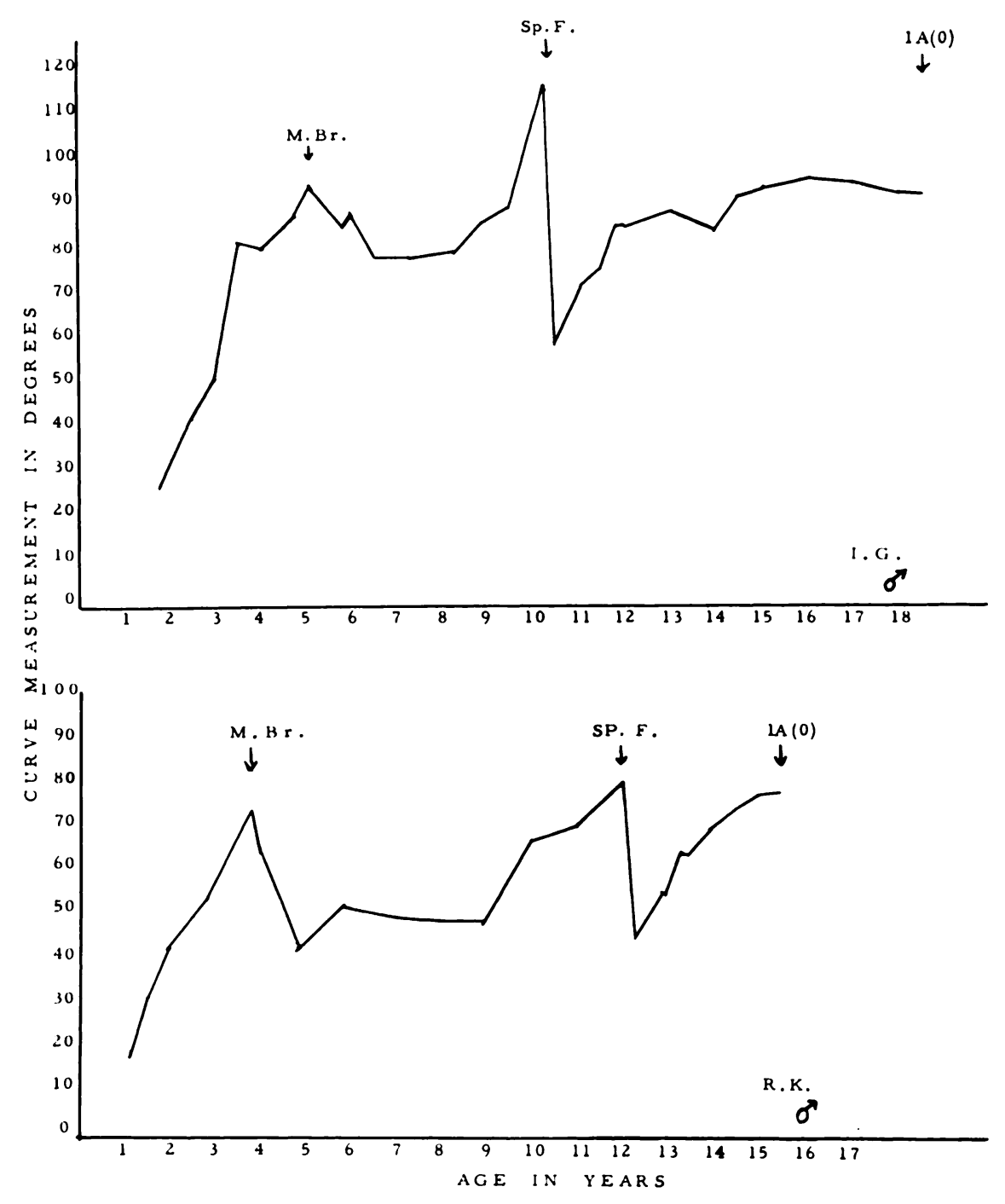

FIG. 18

Progression graphs of two malignant progressive infantile curves showing deterioration during the early and adolescent growth spurts and the delay in ossification of the iliac apophysis. (M.Br. =- Milwaukee brace; Sp.F. = spinal fusion; $1 \mathrm{~A}(0)=$ no ossification of iliac apophysis.)

THE AIM OF TREATMENT OF PROGRESSIVE INFANTILE SCOLIOSIS

The ability to make an early diagnosis and the knowledge of the influence of growth upon progressive scoliosis have an important bearing on treatment. Obviously, a diagnosis of resolving scoliosis indicates nothing more than observation until the spine is straight. But an early diagnosis of progressive scoliosis demands correction without delay, regardless of size or age. The primary aim of early treatment is to control the deformity by correction when it is most easy to do so, and to maintain correction throughout the initial accelerated growth phase in infancy.

VOL. 54 B, NO. 2, MAY 1972 
THE SIGNIFICANCE OF THE DISPARITY IN THE DEGREE OF RIB OBLIQUITY ON THE CONVEX SIDE IN RESOLVING AND PROGRESSIVE CURVES

Denis Browne (1956) put forward the suggestion that an abnormal degree of intra-uterine moulding of the infant may be responsible for infantile scoliotic curves. If the downward rib droop on the convex side were simply the consequence of a sideways bending of the spine in utero, then one would expect a direct ratio between the size of the curve and the degree of rib obliquity in any type of scoliosis. But we find that early resolving and progressive curves of equal degree do not show the same amount of rib droop on the convex side; the initial

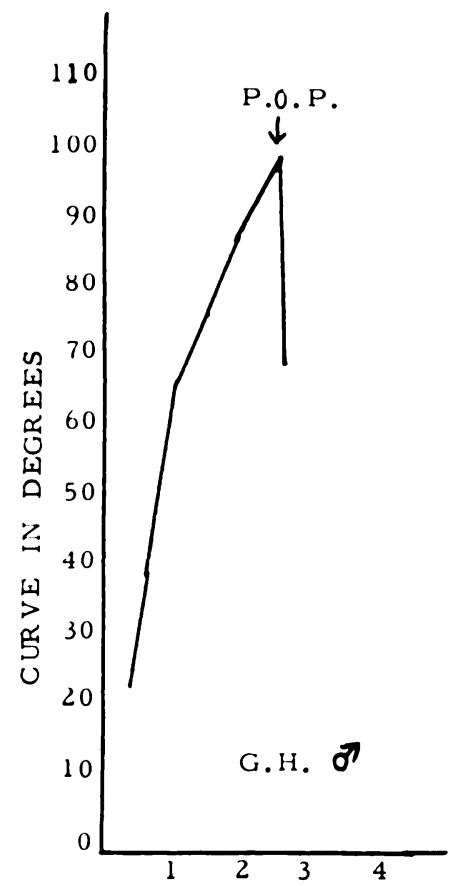

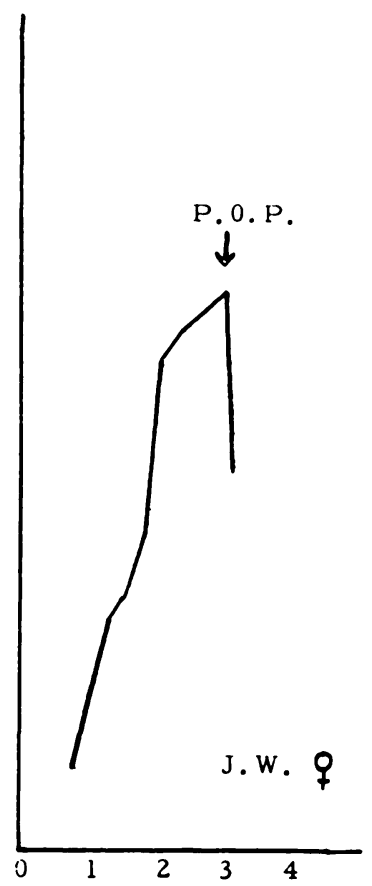

I N

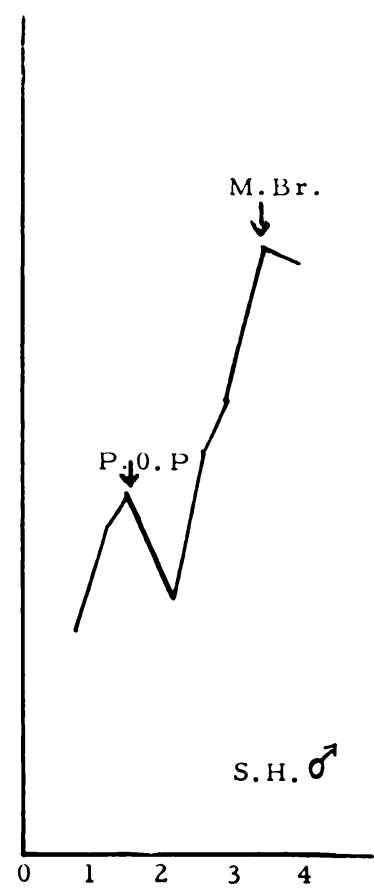

Y E AR S

Fig. 19

Graphs of spinal curves of three children with malignant progressive infantile scoliosis showing the rapid rate of deterioration in infancy. (P.O.P.=plaster-of-Paris; M.Br.=Milwaukee brace.)

rib-vertebra angle difference is consistently greater in the progressive curves (Tables II and III). It is possible that differences in the tissue response to deformation at the costo-vertebral junction could account for the differences in rib obliquity in the two types of curves-ligaments involved in a general connective tissue disorder, as might be the case in progressive curves, would yield more readily to a bending force than ligaments of near normal strength and structure.

Apart from its value in early diagnosis, the rib-vertebra angle serves to direct attention to the importance of the region where rib and vertebra meet in the development of a scoliosis. The experimental work of Langenskiöld and Michelsson (1961) and of Michelsson (1965) drew attention to this region by demonstrating that of the various operations performed on growing rabbits, the ones which consistently produced a scoliosis to the side of operation were those in which the dorsal ends of the ribs or ligaments attaching the ribs to the spine were divided. Lindahl and Raeder (1962) analysed the mechanical forces involved in the development of scoliosis and concluded that a combined lateral flexion and rotation deformity could be produced in their specially constructed model by forces operating upon an area 
which contained transverse processes and dorsal ends of ribs. The radiological evidence of the early rib-vertebra angle difference in scoliosis, thought to be due to a disturbance of the soft tissues in the region of the costo-vertebral joint, supports the experimental and mechanical evidence of the importance of this region in the development of a scoliosis.

\section{SUMMARY}

1. A study of serial radiographs of 138 children with infantile scoliosis starting under the age of two years has resulted in a method of early differentiation between resolving and progressive curves.

2. The method involves careful measurement of the rib-vertebra angles at the apex of the curve and observation of the relationship of the head of the rib to the body of the vertebra as seen in antero-posterior radiographs.

3. The influence of the infantile growth spurt upon progressive curves is examined and the importance of early diagnosis and treatment is stressed.

I wish to thank in particular the Institute of Orthopaedics and the Royal National Orthopaedic Hospital, London, for the grant which made this investigation possible; Mr Charles Manning for directing the research project; Dr Paul Byers and Professor J. I. P. James for helpful criticism; Dr Louis Van der Velde for the translation of Harrenstein's paper; and Mr R. J. Whitley of the Medical Photographic Department and Mrs M. A. Glen Haig of the Medical Records Department for all their help

\section{REFERENCES}

Browne, D. (1956): Congenital Postural Scoliosis. Proceedings of the Royal Society of Medicine, 49, 395.

Conner, A. N. (1969): Developmental Anomalies and Prognosis in Infantile Idiopathic Scoliosis. Journal of Bone and Joint Surgery, 51-B, 711.

Harrenstein, R. J. (1930): Die Skoliose bei Säuglingen und ihre Behandlung. Zeitschrift für orthopädische Chirurgie, 52, 1.

James, J. I. P. (1951): Two Curve Patterns in Idiopathic Structural Scoliosis. Journal of Bone and Joint Surgery, 33-B, 399.

James, J. I. P., Lloyd-Roberts, G. C., and Pilcher, M. F. (1959): Infantile Structural Scoliosis. Journal of Bone and Joint Surgery, 41-B, 719.

Langenskiöld, A., and Michelsson, J.-E. (1961): Experimental Progressive Scoliosis in the Rabbit. Journal of Bone and Joint Surgery, 43-B, 116.

Lindahl, O., and Raeder, E. (1962): Mechanical Analysis of Forces Involved in Idiopathic Scoliosis. Acta Orthopaedica Scandinavica, 32, 27.

Lloyd-Roberts, G. C., and Pilcher, M. F. (1965): Structural Idiopathic Scoliosis in Infancy. Journal of Bone and Joint Surgery, 47-B, 520.

Michelsson, J.-E. (1965): The Development of Spinal Deformity in Experimental Scoliosis. Acta Orthopaedica Scandinavica, Supplementum 81.

Scott, J. C., and Morgan, T. H. (1955): The Natural History and Prognosis of Infantile Idiopathic Scoliosis. Journal of Bone and Joint Surgery, 37-B, 400.

Watson, E. H., and Lowrey, G. H. (1967): Growth and Development of Children. Fifth edition. Chicago: Year Book Medical Publishers, Inc.

VOL. 54 B, NO. 2, MAY 1972 